\title{
Adaptación psicométrica y baremación del módulo de morfología de la Batería de Lenguaje Objetiva y Criterial (BLOC) en niños de 6,7 y 8 años de clase media de Lima
}

Cecilia Ciccia

Universidad de Lima

Lima-Perú

El presente estudio tiene como objetivo la adaptación psicométrica del módulo de morfología de la batería BLOC (Batería de Lenguaje Objetiva y Criterial). Se aplicó el módulo adaptado lingüísticamente a 122 escolares de ambos sexos (32 con trastorno del lenguaje), con edades entre 6 y 8 años, de clase media de Lima metropolitana. Los resultados demostraron que los puntajes de la adaptación eran confiables. Así mismo, se llegó a la conclusión de que dicha prueba posee validez de constructo (evaluada a través del análisis de items y análisis factorial) y validez de criterio (estudiada por medio de la comparación de grupos). Se presentan percentiles del módulo de morfología adaptado.

Lenguaje / desarrollo sintáctico / validez / confiabilidad

\section{Psychometric Adaptation and Scaling of Morphology Module of the Battery of Objective and Criterial Language (BOCL) in children ages 6, 7 and 8, of middle class Lima.}

The present study had as an objective the psychometric adaptation of the module of morphology of the battery BOCL (Battery of Objective and Criterial Language). The module, linguistically adapted, was applied to 122 students of both sexes (32 with language disabilities), of ages between 6 and 8 years, of middle class metropolitan Lima. The results showed that the adaptation scores were reliable. Thus, it was concluded that the test had construct validity (measured through the item analysis and factorial analysis) and criterion validity (studied through the groups' comparison). Percentiles of the adapted module of Morphology are presented.

Language / syntactic development / validity / reliability

Correo electrónico: cc iccia@correo.ulima.edu.pe 
El lenguaje es una habilidad muy ligada a los aprendizajes y a las relaciones interpersonales. Los problemas del lenguaje y la comunicación pueden causar dificultades adaptativas fundamentales a los estudiantes durante su vida escolar. Evaluarlo para el diagnóstico y el tratamiento es imprescindible.

Asimismo, el lenguaje es un fenómeno muy complejo, cuya estructura la forman diversos componentes, como los fonemas, las oraciones, las reglas en la combinación de las palabras y las oraciones, los significados de las palabras y oraciones, entre otras.

Las pruebas de las que se dispone, como el Test de vocabulario en imágenes Peabody, Conceptos básicos de Bohem, Test de comprensión auditiva de Carrow, La prueba de articulación de Moreno, evalúan solo un aspecto del lenguaje: fonológico, comprensión de conceptos, vocabulario, articulación; es decir, miden una de las dimensiones del lenguaje pero no el lenguaje en todos sus aspectos.

Una batería para valorar el lenguaje en varios de sus aspectos, que es muy utilizada en nuestro medio y en otros países, es la Prueba Illinois de Habilidades Psicolingüísticas (ITPA, por sus siglas en inglés), construida como un instrumento diagnóstico cuyo principal objetivo sería poner de manifiesto dificultades de aprendizaje originadas por disfunciones psicolingüísticas. Fue inicialmente ideada para satisfacer las necesidades diagnósticas de niños defi- cientes mentales que debían recibir una educación escolar compensatoria, pues las pruebas clásicas de inteligencia eran inútiles para el diagnóstico diferencial y no permitían distinguir las distintas funciones y niveles de la actividad y de la organización lingüística, que pusieran de manifiesto las dificultades de aprendizaje. Los datos obtenidos a partir de este test difícilmente se pueden proyectar en objetivos concretos para la intervención, por ese carácter global que tiene (Aguado, 1999).

En nuestro medio, la utilización de esta prueba no es recomendada por Matos (1998), quien en una investigación sobre su validez llega a la conclusión de que el ITPA no es un instrumento válido para el diagnóstico e intervención educativa. En este mismo estudio Matos sugiere "iniciar un trabajo de investigación para la elaboración de instrumentos parciales de evaluación de lenguaje con el fin de contar con una batería de exploración lingüística".

En 1999 es publicada la prueba Batería Objetiva y Criterial del Lenguaje (BLOC), elaboraba por Miguel Puyuelo, Elizabeth Wiig, Jordi Remon y Antonio Solas, en Barcelona, en 1997, con conceptos actuales de la psicolingüística en relación con los diferentes componentes del lenguaje (forma, contenido y uso).

Los trabajos de los últimos años ponen de manifiesto la naturaleza multicomponencial del lenguaje, es decir 
que aunque se trate de un fenómeno homogéneo en su superficie, se le considera una federación de componentes, integrados cuando el funcionamiento es normal (Puyuelo, Rondal \& Wiig, 2000).

Esto implica que la evaluación del lenguaje debe basarse en el estudio de contenido (semántica), forma (fonología, morfología y sintaxis) y uso (pragmática) y conviene medir estos diferentes componentes en sus aspectos productivo (expresivo, activo) y receptivo (Rondal \& Serón, 1995).

La prueba BLOC permite conocer las conductas lingüísticas de expresión oral alteradas bien definidas a nivel cualitativo y cuantitativo, atendiendo a los aspectos de déficit que pueden existir con relación al contenido del lenguaje (semántica), a su forma (morfología y sintaxis) y a su uso (pragmática).

Evalúa específicamente aptitudes lingüísticas con menores influencias de aspectos cognitivos (como memoria, percepción, etcétera) que otras pruebas. Asimismo, es una prueba psicopedagógica que permite recoger información de los distintos elementos que intervienen en el proceso de enseñanzaaprendizaje, para identificar las necesidades educativas que presentan los alumnos.

Los resultados de los módulos se pueden comparar entre sí, de manera que es posible analizar los resultados de morfología con los de sintaxis, pragmática o semántica.

\section{OBJetivos}

\section{Objetivos generales}

- Realizar la adaptación psicométrica del módulo de morfología de la Batería de Lenguaje Objetiva Criterial (BLOC) en una muestra de escolares de clase media de Lima metropolitana.

- Elaborar baremos del módulo de morfología de la Batería de Lenguaje Objetiva y Criterial (BLOC), en una muestra de escolares de clase media de Lima metropolitana.

\section{Objetivos específicos}

- Evaluar la adaptación lingüística del módulo de morfología de la Batería de Lenguaje Objetiva y Criterial (BLOC), a través del método de criterio de jueces.

- Calcular la confiabilidad de la Batería de Lenguaje Objetiva y Criterial (BLOC), a través del método de la consistencia interna por medio del coeficiente alfa de Cronbach.

- Analizar la validez de constructo del módulo de morfología de la Batería de Lenguaje Objetiva y Criterial (BLOC), basándose en el método intraprueba a través del análisis de ítems y el análisis factorial.

- Calcular la validez de criterio de la Batería de Lenguaje Objetiva y Criterial (BLOC), a través de la comparación de grupos. 


\section{Batería de lenguaje BloC}

La Batería de Lenguaje Objetiva y Criterial (BLOC) es una prueba estandarizada, elaborada con los conocimientos actuales de la psicolingüística para explorar cuatro grandes aspectos del lenguaje: morfología, sintaxis, semántica y pragmática.

Fue creada para facilitar el estudio y seguimiento de problemas de lenguaje; es un instrumento que combinado con otros y con una adecuada metodología de evaluación, podría ser útil al psicólogo, al terapeuta del lenguaje y a otros profesionales responsables de la evaluación.

Se trata de una prueba idónea para usar en ambientes educativos en labores de detección, valoración, registro y seguimiento de sujetos con distintos grados de retraso del lenguaje (Acosta, 1999).

La prueba se enmarca dentro de las teorías de Bloom y Lahey (1978), Triadó y Fornas (1992), y Rondal y Seron (1982), que describen el lenguaje como la interacción de forma, contenido y uso, términos sinónimos de fonología, sintaxis, morfología, semántica y pragmática (uso interpersonal del lenguaje), así como en otras teorías que definen el estudio de los diferentes componentes del lenguaje. Estas teorías consideran al lenguaje como el producto de la integración de varios subsistemas: el subsistema de los fonemas, el de los lexemas, el gramatical, es decir la morfo- sintaxis, las regulaciones pragmáticas y la organización discursiva. Cada subsistema dispone de una cierta autonomía, como lo demuestran las consideraciones actuales sobre la modalidad neurofuncional del lenguaje y las disociaciones observadas en sus patologías. Esta relativa autonomía entre los subsistemas nos obliga a evaluarlos por separado, sin perder de vista la integración de los componentes en el sistema general del lenguaje (Puyuelo, 2000).

Está conformada por cuatro módulos, uno para cada uno de los componentes del lenguaje que evalúa la prueba. A su vez, cada módulo está formado por diferentes números de bloques, que son grupos de habilidades lingüísticas y comunicativas evaluadas en cada uno.

Tabla 1

Formato de BLOC

\begin{tabular}{lccc}
\hline & Bloques & Items & $\begin{array}{c}\text { Total de } \\
\text { ítems }\end{array}$ \\
\hline Morfología & 19 & 10 & 190 \\
Sintaxis & 18 & 10 & 180 \\
Semántica & 8 & 10 & 80 \\
Pragmática & 13 & 10 & 130 \\
\hline
\end{tabular}

En el caso del módulo de morfología (módulo que estudia este trabajo) contiene 19 bloques, cada uno con diez ítems para evaluar los conocimientos de flexión y formación de palabras.

Los ítems que componen la batería buscan provocar o inducir una determinada respuesta en el individuo en relación con sus habilidades lingüísticas. 
Es un instrumento que permite al clínico valorar tanto los aspectos cualitativos como cuantitativos del lenguaje, al proporcionar tres tipos de baremos en un mismo individuo: baremos normativos (permiten conocer el nivel del individuo en relación con una determinada habilidad lingüística con referencia a la edad), puntuación criterial (permite conocer el nivel del individuo en relación con una determinada habilidad lingüística) y curva de desarrollo (permite conocer cuantitativamente y cualitativamente la evolución del individuo en el tiempo en relación con una determinada habilidad lingüística, así como realizar una representación gráfica de esta). Esta versatilidad en cuanto a las puntuaciones implica que, por ejemplo, se disponga de baremos para el bloque de morfología de verbos regulares en tiempo presente, si solo se quiere evaluar ese bloque (Puyuelo, 2000).

Comprende un amplio intervalo de edad (5 a 14 años). Por ello sirve para recoger la evolución de un mismo individuo durante un periodo largo de tiempo.

Ha demostrado tener buenas cualidades psicométricas.

\section{Módulo de morfología de BLOC}

Los autores de la prueba parten de un modelo que considera que una prueba que evalúe los conocimientos morfológicos de un hablante nativo debe centrarse en "aspectos de estructura de la palabra". En este módulo se evalúan los conocimientos de flexión y formación de palabras. Los diferentes bloques que forman el módulo miden el uso de reglas de plurales, posesivos, formas personales de tercera persona, verbos regulares y formas irregulares de sustantivos y verbos, así como la formación de sustantivos complejos y derivaciones adjetivales. De esta manera mide el conocimiento y el uso de las reglas morfológicas.

En este módulo se han estudiado las diferentes formas morfológicas del castellano, tomando como base los cambios del radical (morfema básico de la palabra) y los morfemas flexivos y sufijos derivativos que lo complementan.

\section{Morfología}

La morfología es una disciplina lingüística que se ocupa del estudio de la estructura de la palabra y de las relaciones que se producen en el seno de esta (Martínez, 1998).

Las palabras se descomponen en componentes más pequeños, a los que se les denomina lexemas o radicales y morfemas.

Los lexemas reflejan el contenido semántico y pertenecen a un conjunto de palabras de inventario abierto, es decir podemos añadir constantemente nuevas unidades a este inventario.

Los morfemas determinan el significado de los lexemas, carecen de un significado pleno pero poseen un signi- 
ficado ocasional y/o de tipo gramatical; pertenecen a inventario cerrado.

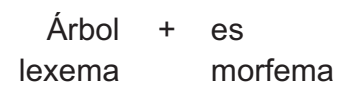

Los morfemas se clasifican en libres y trabados. Los libres aparecen sin necesidad de unirse a un lexema, como, por ejemplo: la, para, con, y, etcétera. Los trabados, también llamados dependientes, no pueden aparecer aisladamente en la oración, sino que siempre forman parte de un lexema.

Existen dos tipos de morfemas trabados:

- Derivativos: prefijos, sufijos.

- Flexivos: género, número y desinencias verbales.

Los morfemas derivativos tienen un carácter predominantemente léxico, los flexivos predominantemente gramatical (Real Academia Española, 1979).

A su vez, los morfemas trabados pueden ser de dos clases:
- Obligatorios: su presencia es necesaria en la formación correcta de la palabra, como por ejemplo: número, persona, etcétera.

- Facultativos: su presencia es optativa para la correcta formación de la palabra, como, por ejemplo: aumentativo, dimiuntivo, etcétera.

Los significados de una oración se obtienen por la combinación de las palabras, según reglas determinadas. Existe relación inversa entre orden y riqueza morfológica; las lenguas con mayor cantidad y variación de morfemas necesitan apoyarse menos en el orden para precisar el significado de una oración. Así, el inglés es mucho más rígido respecto del orden de los constituyentes de la oración que el español, por la menor riqueza morfemática de aquel (Aguado, 1999).

\section{El sustantivo}

El sustantivo posee la siguiente estructura:

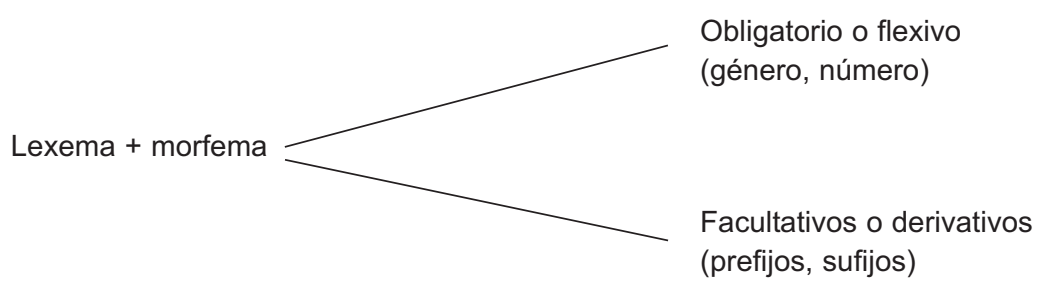


Los sustantivos están formados por morfemas que indican género y número, y también por morfemas facultativos, que pueden aparecer o no: los sufijos y prefijos. Así, de acuerdo con la forma, los sustantivos se clasifican en: simples compuestos, primitivos, derivados y parasintéticos.

\section{El verbo}

El verbo es el núcleo del sintagma verbal y está formado por un lexema que aporta el significado, por morfemas flexivos (también llamados desinencias), que son morfemas obligatorios y privativos del verbo que indican tiempo y modo, y además por morfemas flexivos de número y persona (en el caso del verbo, suele aplicarse la denominación de desinencias a los morfemas de número y persona, el de $c a$ racterística a los de modo y tiempo). Entre el lexema y la desinencia se encuentra la vocal temática, que confiere información sobre la conjugación a la que pertenece el verbo (Martínez, 1998); indica si este es de la primera, segunda o tercera conjugación, según sea -ar, -er, -ir, respectivamente. El verbo, pues, posee la siguiente estructura:

Lexema + vocal temática + desinencias

(o morfemas flexivos)

\section{Formas no personales del verbo}

Las formas no personales del verbo son aquellas que carecen de morfema de persona, es decir, infinitivo, gerundio y participio. Estos verbos realizan, dentro de la oración, funciones sintácticas: la propia del verbo, y la del nombre en el caso del infinitivo, la de adverbio en el caso del gerundio y la de adjetivo en el caso del participio (Martínez, 1998).

\section{Conjugación de los verbos}

Los verbos, por su conjugación, pueden ser regulares e irregulares. Los verbos regulares se conjugan sin cambios en el radical y solo la desinencia se modifica según formas fijas que son las de la mayoría de los verbos.

En el caso de la conjugación de los verbos irregulares el radical del verbo se altera, o la desinencia no es la de la mayoría de los verbos o suceden ambas cosas a la vez.

\section{El adjetivo}

Los adjetivos, así como los adverbios, describen cualidades de acciones, acontecimientos, objetos, personas $\mathrm{y}$ animales (Aguado, 1999).

Los adjetivos se dividen en dos grandes grupos: calificativos y determinativos (Martínez, 1998). 
a) Adjetivos calificativos:

Aportan al nombre un significado más preciso y específico.

La estructura del adjetivo calificativo es semejante a la del nombre. Los lexemas aportan el contenido semántico, los morfemas obligatorios indican género y número, y los morfemas facultativos indican si son sufijos o prefijos (Martínez, 1998). Tanto adjetivo como sustantivo tienen unos mismos morfemas de número (Real Academia Española, 1979), no obstante, podemos observar que, a diferencia del sustantivo, el número del adjetivo es variable, ya que viene impuesto en la concordancia con el sustantivo al que acompaña (Martínez, 1998).

\section{Grados del adjetivo}

Una de las cualidades del adjetivo es que admite el morfema de grado que le permite hacer comparaciones (Martínez, 1998). En nuestro idioma estos diferentes grados se expresan por medios morfológicos o sintácticos, según los casos (Real Academia, 1979).

Los grados del adjetivo son: positivo, comparativo y superlativo.

Con relación al adjetivo comparativo, que establece comparación entre dos o más cualidades o entre un sustantivo con su adjetivo y otro sustantivo con su sustantivo, nos valemos de recursos sintácticos y no morfológicos.

Los superlativos tienen dos variantes: superlativo relativo y superlativo absoluto (carísimo, muy alto), ísimo /ísima es de naturaleza gramatical y se considera como un morfema flexivo (Real Academia, 1979).

\section{b) Adjetivo determinativo}

Los determinativos delimitan el significado del sustantivo o del grupo nominal. En general, salvo algún caso como el de mucho y poco, los determinantes no admiten sufijos, ni prefijos, ni adverbios de grado.

Los determinativos, como Ochoa (2001) indica, se pueden clasificar en: artículos, demostrativos, posesivos (apocopados y plenos), numerales (cardinales y ordinales) e indefinidos.

En este trabajo solo se desarrollará el adjetivo determinativo posesivo: formas apocopadas (mi, tu, su y sus respectivos plurales) y formas plenas (mío, tuyo, suyo, nuestro, vuestro, y sus respectivos plurales y femeninos).

\section{El pronombre}

Los pronombres son morfemas con significación ocasional; es decir, su significado depende de las relaciones deícticas con alguna entidad. Entre los pronombres que posee el castellano, encontramos los llamados personales. Estos pronombres indican las personas del discurso. Los pronombres personales muestran, en la superficie, un sistema de caso explícito que hemos heredado del latín. Así, podemos encontrar que hay pronombres de caso nominati- 
vo, los cuales siempre ocupan la posición sujeto de la oración: pronombres personales nominativos (yo, tú, usted, él, ella, nosotros, ustedes, él, ella), pronombres personales acusativos (me, te, lo/la/le/se, nos, ustedes, los/las/les/se), y pronombres personales dativos (mi/conmigo, ti/contigo, si/consigo).

\section{MeCANISMo de CREACIÓN LÉXICA}

Las palabras se forman mediante reglas de combinación morfológica. Estas reglas son mecanismos que suponen una gran dificultad en las patologías en las que se ven implicados los niveles morfológicos y sintácticos (Martínez, 1998). Estos mecanismos son la derivación, la composición y la parasíntesis.

\section{a) Derivación}

Consiste en la adjunción de un morfema derivativo a la base léxica, ejemplo: candorosa, blancura, panadería, reino, etc.

La derivación puede afectar a sustantivos, verbos y adjetivos.

A partir de una palabra primitiva (palabra que no procede de otra palabra) podemos formar nuevas palabras añadiéndoles prefijos o sufijo. Los prefijos se sitúan delante del lexema, ejemplo: devolver, reponer, contraponer. Los sufijos son morfemas que se ponen detrás del lexema (violinista, florecer, plegable, etcétera).

\section{b) Composición}

Consiste en unir dos o más palabras, creando un nuevo término. Ejemplo: bocacalle, anteayer, quitasol.

\section{c) Parasíntesis}

Consiste en la formación de nuevas palabras uniendo los procesos de composición y derivación. Por ejemplo, picapedrero.

\section{LA PALABRA: Primitivos LÉXICOS}

La unión de dos o más morfemas hacen posible matizaciones muy finas del significado de las palabras (De Vega \& Cuetos, 1999). Las palabras se almacenan en nuestro léxico mental y los psicólogos han estudiado cómo lo hacen para ser utilizadas en la comprensión y/o producción del lenguaje (Berko, 1999). La cuestión acerca de si son las palabras completas o los morfemas aislados los que funcionan como primitivos léxicos (la mínima forma en la cual se almacena una palabra en el léxico mental) cuenta con dos hipótesis alternativas: a) cada palabra (incluida la polimorfémica) posee su propia entrada léxica, conocida como lexema, y b) los morfemas constituyentes se almacenan individualmente en el léxico de tal forma que las palabras se descomponen (en la comprensión) o se componen (en la producción).

Con la primera hipótesis, el enfoque lexemático de la palabra, el sistema cognitivo invertiría mucho espacio en 
el léxico para el mantenimiento de las numerosas variaciones de las palabras, así palabras como libro, librero, librería, cada una de ellas tendría su propia entrada léxica. Con la segunda hipótesis, la teoría de los morfemas como primitivos, el sistema cognitivo requiere menor espacio de almacenamiento, pero mayor capacidad para llevar a cabo los procesos de construcción (en la producción del discurso) o descomposición (en la comprensión) de las palabras en morfemas constituyentes.

Según parece el procesamiento léxico trata de adoptar un equilibrio óptimo entre la economía cognitiva en la memoria y la economía en el ensamblaje y descomposición de las palabras plurimorfémicas. Los sufijos flexivos como -ndo o $-s$, que no cambian de forma acusada el significado o la categoría gramatical de los morfemas base, es probable que se vayan adjuntando (o apartando) durante el procesamiento. Sin embargo, las palabras plurimorfémicas de frecuente aparición y aquellas con morfemas derivativos a menudo poseen entradas léxicas separadas de sus morfemas raíces (Berko, 1999).

\section{Desarrollo morfológico}

\section{El género gramatical}

En el castellano, el género gramatical de los sustantivos se hacen arbitrariamente, así, no hay razón para especificar la silla como femenino y el helado como masculino. En el lenguaje ini- cial es más coherente pensar que hay aprendizaje léxico y no morfemático, es decir que el niño aprendería la versión masculina y la femenina como si se tratase de dos palabras, y no como una raíz y dos flexiones (Clemente, 1995). El género surge vinculado a los sustantivos y más tarde a los artículos (Rondal \& Seron, 1995).

Para algunos autores el género es el primer morfema que producen los niños, quizá porque en castellano se hace con una simple alternancia vocálica que podría facilitar su adquisición (el plural requiere de $-s$ al final de la sílaba, tarea no muy sencilla en edades tempranas) (Clemente, 1997).

\section{El número}

El uso de los plurales se logra a los tres años, excepto algunos errores (Clemente, 1997). Sin embargo, Brown encuentra este uso desde los 18 meses para palabras imitadas que siempre se presentan en plural, como por ejemplo uvas, papas, en este momento no hay evidencias de que los niños conozcan las reglas de transformación del singular en plural, el niño estaría tratando la versión del plural como si fuese una palabra y no una raíz con flexión. En trabajos sobre el uso de plurales en palabras sin sentido, como en investigaciones planteadas por Berko en 1958 (Berko y Berstein, 1999) se observa que los niños tienden a sobrerregular estas palabras sobre las reglas más frecuentes del castellano, como se puede 
advertir también en datos recogidos del habla espontánea en palabras poco familiares.

\section{El pronombre}

Es considerado un elemento controversial, pues aparece en el discurso como sustituto de otros elementos que aparecen implícitos en la comunicación.

El dominio de los pronombres por parte de los hablantes exige conocimientos de carácter semántico-pragmático. El pronombre tú es el más precoz probablemente, podría ser más fácil de imitar cuando se cambia el tú. Los niños que no hacen cambios referenciales cometen un error frecuente, error que se observa en los niños autistas (Clemente, 1997).

Hasta los tres años no hay clara diferenciación del yo, sin embargo, sí hay referencia personal, pues el niño se nombra a sí mismo como [e nene] o [a nena] el nene o la nena o por su nombre (Clemente, 1997). Bloom y colaboradores (1978) (citado en Clemente, 1997) describen este uso nominal de los niños. Alison, la hija de Bloom, a los 22 meses usaba sustantivos referidos a otras personas en lugar del pronombre de segunda persona: [ma ma abe] mamá abre (Clemente, 1995). Muy próximo a los tres años la identidad personal está afianzada, el pronombre yo se usa con mayor frecuencia (Clemente, 1997).

Entre los 10 y los 18 meses los niños usan los pronombres demostrativos de primera aparición (ejemplo: este, ese, esa, aparecen solos en la frase).
Entre aproximadamente los 2,6 y 3 años pueden encontrarse en el habla del niño los pronombres personales de primera, segunda y tercera persona del singular, y los posesivos mío y tuyo (Acosta, 1999). También aproximadamente a los 2,6 años aparecen las formas objetivas de los pronombres, ejemplo: tráelo, mátale, además se observa el uso de las formas conmigo y contigo. Entre los 2,9 y 3,0 años el pronombre reflexivo se usa por primera vez, ejemplo: se cayó, y los objetos directos e indirectos son usados con mayor frecuencia. A los 3,6 años la mayoría de construcciones reflexivas constan de te y algunas de se (Hernández-Pina, 1984; Gonzales, 1978 \& Montes Giraldo, 1974, citados en Rodríguez \& Berruecos, 1993). Los posesivos grupales como nuestro y vuestro se dan alrededor de los cuatro años (Clemente, 1995). Cerca de los 5 años, los pronombres están bien establecidos (Hernández-Pina, 1984; Gonzales, 1978 \& Montes Giraldo, 1974, citados en Rodríguez \& Berruecos, 1993). Sin embargo, antes de los 6-7 años o más, el niño no utiliza sistemáticamente marcas de género y número en la identificación del sustantivo al que remite el pronombre (Rondal \& Seron, 1995).

\section{El verbo}

Los tiempos verbales iniciales que se utilizan son las formas imperativa e indefinida. 
Las formas perifrásticas aparecen ya a los 24 meses; son las formas más frecuentes y precoces usadas para expresar futuro [ir $+\mathrm{a}+$ verbo].

Desde los 26 meses se registra el presente del indicativo (llora), el que domina el sistema verbal infantil durante los primeros años y le permite al niño declarar, informar pedir y preguntar, funciones todas ellas típicas del diálogo (Clemente, 1997). Además, alrededor de esta edad -también dentro del modo indicativo- se registra el pretérito perfecto (lloré) (Acosta, 1999).

Alrededor de los 3,0 años, los niños ya se expresan en presente, pasado y futuro, igualmente, el gerundio y el futuro perifrástico están establecidos. Las formas imperfectas comienzan a solidarizarse (Cohen, 1980; y González, 1978, citados en Rodríguez \& Berruecos, 1993).

La complejidad del futuro procede de la dificultad cognitiva de hipotetizar sobre realidades futuras. De las dos formas de hacer futuro en castellano, la más usada por los niños es la perífrasis [ir $+\mathrm{a}+$ verbo]. La otra alternativa, los futuros con $-r$ (comerá) es tardía $\mathrm{y}$ menos frecuente y los primeros registros son imitados (ya verás) repetido varias veces por un niño de tres años en una misma sesión, los espontáneos se observan después de los cinco años (Clemente, 1997).
El subjuntivo es el modo de la irrealidad, por eso es una forma semánticamente compleja para los niños. Los usos correctos en las situaciones que lo exigen solo empiezan a ser generales a partir de los seis años, el modo subjuntivo y sus tiempos tienen costo cognitivo y se refleja en su retraso (Clemente, 1997).

\section{CONFIABILIDAD Y VALIDEZ DE LA BATERÍA BLOC ORIGINAL}

\section{Confiabilidad de la batería BLOC original}

En la prueba BLOC original se obtuvieron distintos coeficientes de confiabilidad para cada una de las agrupaciones de ítems y, paralelamente, todos estos valores se replicaron para cada uno de los niveles escolares o grupos de los baremos (9 grupos de edades). Para el cálculo de estos coeficientes de confiabilidad se empleó el coeficiente KR20 para bloques y módulos y el indicador $H$ para los bloques. Se trata de coeficientes de consistencia interna y de homogeneidad que se obtienen tras aplicar la prueba en una sola ocasión. En la tabla siguiente se muestran los principales indicadores de confiabilidad mediante el coeficiente KR20 de cada uno de los cuatro módulos de la batería. 
Tabla 2

Confiabilidad mediante el KR20 de cada uno de los cuatro módulos

\begin{tabular}{lccc}
\hline Módulo & $\mathrm{P}$ & Discr. & KR20 \\
\hline Semántica & 0.83 & 0.34 & 0.98 \\
Sintaxis & 0.66 & 0.53 & 0.98 \\
Morfología & 0.67 & 0.49 & 0.97 \\
\hline
\end{tabular}

Todos los valores superan el nivel de 0.9 , especialmente morfología y sintaxis.

En general, respecto a los indicadores de confiabilidad de los bloques solo dos han mostrado un bajo nivel: el bloque 4, de semántica ("instrumental"), y el bloque 1, de morfología ("plurales": singulares acabados en vocal"). En ambos casos, como los autores argumentan, la facilidad demostrada por los ítems puede ser el motivo de su menor consistencia, ya que la confiabilidad está muy determinada por la variabilidad de los datos y con niveles de acierto elevados, esta se reduce considerablemente (Puyuelo, Wiig, Pinsach \& Pérez, 1998).

\section{Validez de la batería BLOC original}

La prueba BLOC es una prueba originalmente validada a nivel de contenido (Puyuelo, 2000). En el caso de módulo de morfología la lectura de sus ítems permite comprobar que las respuestas esperadas implican diversas habilidades psicolingüísticas. La estructura de los ítems y bloques deja patente el tipo de respuesta deseada sin que pueda ser motivo de confusión la habilidad medida por cada agrupación de reactivos. La BLOC se ha diseñado para ser muy sensible a la edad y al proceso evolutivo y de adquisición de las habilidades lingüísticas. No se trata de una prueba en los límites de una o más dimensiones psicológicas con definiciones ambiguas. Su contenido está bien definido, al igual que la reacción esperada en sus ítems (Puyuelo, Wiig, Renom, Solanas, 1998). Sin embargo, las puntuaciones de BLOC obtenidas en varias submuestras de individuos fueron comparadas con otras dos pruebas: el Peabody Picture Vocabulary Test (PPVT) y la batería WISC-R (Weschler). Los coeficientes obtenidos mostraron relaciones muy significativas para los cuatro módulos y la mayoría de los bloques con los subtests de vocabulario y aritmética del WISC y con las puntuaciones totales del PPVT. Los valores más significativos se obtuvieron en los módulos de sintaxis y morfología. También ambas pruebas se complementaron con otros criterios: la valoración, según la edad y grado escolar como indicadores del desarrollo lingüístico (Puyuelo, Solanas, Renom \& Wiig, 1998). Los datos mostraron una fuerte sensibilidad de los cuatro módulos ante esta variable. Morfología y sintaxis correlacionaron de forma superior que semántica y pragmática.

También se efectuó una última verificación con la variable sexo, a efectos de conocer posibles sesgos. En ningún 
caso se hallaron diferencias significativas entre las puntuaciones de los cuatro módulos para niños y niñas.

En general, la validez de BLOC ha quedado establecida desde su origen por el contenido de la batería. Estos resultados refuerzan las posibilidades de la batería en la detección de niveles adecuados a normas de edad y escolares.

\section{MÉTodo}

\section{Muestra}

La población seleccionada estuvo representada por alumnos de 6,7 y 8 años, pertenecientes a centros educativos regulares y de educación especializada, de clase socioeconómica media de Lima metropolitana.

Para reunir a los sujetos se seleccionaron colegios parroquiales y otros similares, donde no se imparten cursos en inglés o en otra lengua.

En lo que respecta al género, no se consideró como criterio de estratificación.

Es importante mencionar que dicha muestra fue seleccionada siguiendo las pautas del muestreo no probabilístico, ya que para seleccionar a los sujetos que formaron parte, no se tomaron elemen- tos aleatorios. La muestra fue elegida de manera intencional, teniéndose en cuenta la facilidad de accesos a esta. Se siguieron los siguientes criterios de inclusión:

- Grupos de escolares pertenecientes a colegios mixtos parroquiales cuyos cursos académicos se imparten en español.

- Edades entre los 6 y 8 años.

- Sin limitaciones intelectuales (con CI general normal).

- Para el grupo de niños con trastorno de lenguaje se tuvo en cuenta que contaran con el diagnóstico de "trastorno de lenguaje, expresivo y/o comprensivo". Todos los alumnos pertenecientes a este grupo se ubicaron dentro de escuelas especializadas.

Como se observa en la tabla 3 , fueron seleccionados 122 niños, 32 de ellos con trastornos de lenguaje. Los 90 alumnos sin trastorno de lenguaje lo formaron 30 niños en cada uno de los tres grupos: 6, 7 y 8 años.

De los 32 participantes que conformaron la población con trastorno del lenguaje del lenguaje 14 constituyeron parte del grupo de 6 años, 12 del grupo de 7 años y 6 del grupo de 8 años.

Tabla 3

Distribución de la muestra por edad y por grupo según diagnóstico

\begin{tabular}{lcccc}
\hline Alumnos & $\begin{array}{c}\text { Edades } \\
6 \text { años }\end{array}$ & 7 años & 8 años & Total \\
\hline Sin trastorno de lenguaje & 30 & 30 & 30 & 90 \\
Con trastorno de lenguaje & 14 & 12 & 6 & 32 \\
Total & 44 & 42 & 36 & 122 \\
\hline
\end{tabular}




\section{Instrumento}

El instrumento utilizado para la recolección de los datos fue el Módulo de Morfología de BLOC. Este, como los otros módulos que conforman la batería, fueron elaborados en Barcelona por Miguel Puyuelo Sanclemente, Elizabeth H. Wiig, Jordi Renom Pinsach, y Antonio Solas Pérez. La batería fue publicada en 1998, por la editorial Masson, en Barcelona. Se elaboró como una alternativa para evaluar el desarrollo morfológico, sintáctico, semántico y pragmático del lenguaje. Es de aplicación individual y la batería completa requiere de cuatro horas para su administración.

El módulo de morfología de BLOC (requiere una hora para su administración) fue desarrollado para estudiar la estructura de las formas gramaticales cuya unidad básica es el morfema. Evalúa los conocimientos de flexión y formación de palabras. El módulo está formado por 190 ítems, representado por una figura que ubica al alumno alrededor del contexto dentro del cual se enmarca la pregunta. Cada uno de los 19 bloques que conforman el módulo de morfología tiene diez ítems. Los bloques son los siguientes:

Bloque 1. Plurales. Singulares acabados en vocal.

Bloque 2. Plurales. Singulares acabados en consonante e invariables.

Bloque 3. Adjetivo.

Bloque 4. Formas verbales regulares: Presente.
Bloque 5. Formas verbales regulares:

Pasado

Bloque 6. Formas regulares. Futuro

Bloque 7. Formas verbales regulares: Imperfecto

Bloque 8. Formas verbales irregulares:

Presente

Bloque 9: $\quad$ Formas verbales irregulares:

Pasado

Bloque 10: Formas verbales irregulares:

Futuro.

Bloque 11: Participios

Bloque 12: Comparativos y superlativos

Bloque 13: Sustantivos derivados: profesiones

Bloque 14: Sustantivos derivados.

Bloque 15: Adjetivos derivados.

Bloque 16: Pronombres personales:

Sujetos

Bloque 17: Pronombres personales en función de objeto.

Bloque 18: Reflexivos

Bloque 19: Posesivos

Se aplica individualmente y la mayoría de los ítems sólo admiten una respuesta. En la mayoría de los casos, el enunciado ya lleva la palabra de referencia a partir de la cual se debe configurar la respuesta.

Las hojas de respuestas permiten registrar los resultados obtenidos en cada uno de los ítems correspondientes a cada bloque:

1: respuesta positiva (acierto)

0 : respuesta negativa (error)

\section{Procedimiento}

En primer lugar se llevó a cabo la adaptación lingüística de la prueba, para lo cual fue revisada por ocho jueces, todos especialistas en el trabajo terapéutico del lenguaje. Una vez que 


\section{Ciccia}

se obtuvieron las evaluaciones hechas por los jueces se aplicó la fórmula del coeficiente $V$ de Aiken para identificar que ítems deberían ser modificados según sus sugerencias (Escurra, 1988).

Después de hacer los cambios respectivos (ver tabla 4), se elaboró la versión revisada, obteniéndose así la versión final.

Una vez elaborada la adaptación se contactaron los colegios con los criterios de inclusión y tres colegios de edu- cación especializada en niños con dificultades de lenguaje y aprendizaje. La administración se realizó de manera individual y tomó un tiempo aproximado de una hora por cada niño, la misma que se dividió en dos sesiones de media hora.

En la tabla 4 se presenta el estado de palabras que sugirieron los jueces sean modificados en la prueba original.

Todos los términos sugeridos para el cambio fueron remplazados.

Tabla 4

Listado de palabras sugeridas para ser cambiadas

\begin{tabular}{|c|c|c|c|c|c|c|c|}
\hline Bloque & Ítem & Palabra original & Palabra sugerida & Acuerdo & Desacuerdo & $\begin{array}{l}V \text { de } \\
\text { Aiken }\end{array}$ & Decisión \\
\hline 1 & 8 & Esquí & Ají & 7 & 1 & $.88^{*}$ & A \\
\hline 2 & 5 & Autobús & Microbús & 8 & 0 & $1.0^{*}$ & $A$ \\
\hline \multirow[t]{2}{*}{3} & 7 & Nata & Crema & 8 & 0 & $1.0^{*}$ & $A$ \\
\hline & 9 & Coche & Carro & 8 & 0 & $1.0^{*}$ & $A$ \\
\hline \multirow[t]{2}{*}{4} & 7 & Vosotras / corréis & Ustedes / corren & 8 & 0 & $1.0^{*}$ & $A$ \\
\hline & 8 & Vosotras / oléis & Ustedes / huelen & 8 & 0 & $1.0^{*}$ & $A$ \\
\hline 5 & 7 & Vosotras / corristeis & Ustedes & 8 & 0 & $1.0^{*}$ & A \\
\hline \multirow[t]{2}{*}{6} & 7 & Vosotras & Ustedes & 8 & 0 & $1.0^{*}$ & $A$ \\
\hline & 8 & Vosotras & Ustedes & 8 & 0 & $1.0^{*}$ & $A$ \\
\hline \multirow[t]{4}{*}{7} & 3 & Visteis & Vieron & 8 & 0 & $1.0^{*}$ & A \\
\hline & 4 & Visteis & Vieron & 8 & 0 & $1.0^{*}$ & $A$ \\
\hline & 7 & Os / vosotras / corríais & Las/ustedes/corrían & 8 & 0 & $1.0^{*}$ & $A$ \\
\hline & 8 & Os/ vosotros / olíais & Las / ustedes / olían & 8 & 0 & $1.0^{*}$ & $A$ \\
\hline \multirow[t]{2}{*}{8} & 3 & Zoo & Zoológico & 8 & 0 & $1.0^{*}$ & $A$ \\
\hline & 7 & Vosotros / sois & Ustedes/ son & 8 & 0 & $1.0^{*}$ & $A$ \\
\hline \multirow[t]{2}{*}{10} & 9 & Vosotros / sabréis & Ustedes /sabrán & 8 & 0 & $1.0^{*}$ & A \\
\hline & 10 & Tarde / merienda & Mañana / desayuno & 7 & 1 & $.88^{*}$ & $A$ \\
\hline 11 & $I D^{*}$ & Valla & Reja & 8 & 0 & $1.0^{*}$ & A \\
\hline 12 & 3 & Pastel & Torta & 8 & 0 & $1.0^{*}$ & $A$ \\
\hline 13 & 6 & Vallas & Rejas & 8 & 0 & $1.0^{*}$ & $A$ \\
\hline \multirow[t]{2}{*}{16} & 2 & Lanza/conduzca/coche & Tira /maneje/carro & 8 & 0 & $1.0^{*}$ & $A$ \\
\hline & 6 & Vosotros & Ustedes & 8 & 0 & $1.0^{*}$ & $A$ \\
\hline 18 & 3 & Hacéis & Hacen & 8 & 0 & $1.0^{*}$ & $A$ \\
\hline \multirow[t]{2}{*}{19} & 7 & Vuestros & Sus & 8 & 0 & $1.0^{*}$ & $A$ \\
\hline & 9 & Coche & Carro & 8 & 0 & $1.0^{*}$ & $A$ \\
\hline
\end{tabular}

${ }^{*} \mathrm{p}<.05$

ID = ítem de demostración 
ANÁLISIS Y DISCUSIÓN DE LOS

\section{RESULTADOS}

Para el análisis psicométrico de los resultados de la investigación, se procedió en primer lugar a calcular el grado de confiabilidad por consistencia interna del Módulo de Morfología de BLOC así como de cada uno de los bloques que lo conforman para la muestra total y para cada uno de los grupos de edad. Seguidamente se calculó la validez de constructo y de criterio; finalmente, se elaboraron los baremos respectivos.

\section{Confiabilidad}

La consistencia interna fue obtenida mediante el coeficiente alfa de Cronbach (Nunnally, 1991 y Muñiz,1996); se estimó la confiabilidad para la muestra de estandarización y para la submuestras por diagnóstico y edad. El alfa para la muestra total de estandarización fue de .88. Los coeficientes de consistencia interna obtenidos según diagnóstico son .85 para el grupo sin trastorno de lenguaje y de .87 para el grupo con trastorno de lenguaje. Los coeficientes de consistencia interna que se obtuvieron para los grupos fueron: .83 para el grupo de 6 años, .83 para el grupo de 7 años y de .80 para el grupo de 8 años (véase tabla 5).

El análisis de los coeficientes alfa de Cronbach para el puntaje total eliminando el bloque, correspondiente a los 19 bloques del módulo de morfología de BLOC y considerando la muestra total se presentan en la tabla 6 .

El análisis del Módulo de Morfología de la Batería de Lenguaje Objetiva y Criterial (BLOC) muestra que los bloques que presentan mayor dificultad son el bloque 17, relacionado con pronombres personales en función de objeto $(\mathrm{M}=1.02$ y D.S. $=1.89)$, y el bloque 12, que mide comparativos $y$ superlativos $(\mathrm{M}=1.23$ y D.S. $=1.98)$. Los bloques fáciles son el bloque 3, relacionado con el uso de morfemas de género en los adjetivos $(\mathrm{M}=9.54 \mathrm{y}$

Tabla 5

Consistencia interna del módulo para cada uno de los grupos de estudio

\begin{tabular}{|c|c|c|c|c|c|}
\hline \multirow{3}{*}{$\begin{array}{l}\text { Muestra } \\
\text { total } \\
\mathrm{N}=122\end{array}$} & \multicolumn{3}{|c|}{ Edades } & \multicolumn{2}{|c|}{ Diagnóstico } \\
\hline & 6 años & 7 años & 8 años & $\begin{array}{c}\text { Grupo sin } \\
\text { transtorno } \\
\text { del lenguaje }\end{array}$ & $\begin{array}{c}\text { Grupo con } \\
\text { transtorno } \\
\text { del lenguaje }\end{array}$ \\
\hline & $N=30$ & $N=30$ & $N=30$ & $\mathrm{~N}=90$ & $N=32$ \\
\hline Alfa $=.88$ & Alfa $=.83$ & Alfa $=.83$ & Alfa $=.80$ & Alfa $=.85$ & Alfa $=.87$ \\
\hline
\end{tabular}


Tabla 6

Consistencia interna de los bloques del módulo para la muestra total $(\mathrm{N}=122)$

\begin{tabular}{lcccc}
\hline Bloque & M & D.E. & $\begin{array}{c}\text { Correlación } \\
\text { item-test } \\
\text { corregida }\end{array}$ & $\begin{array}{c}\text { Alfa si el ítem } \\
\text { es eliminado }\end{array}$ \\
\hline Bloque 1 & & .95 & .36 & .87 \\
Bloque 2 & 6.62 & 1.82 & .53 & .87 \\
Bloque 3 & 5.93 & 1.22 & .28 & .87 \\
Bloque 4 & 9.54 & 3.20 & .20 & .88 \\
Bloque 5 & 6.07 & 2.13 & .45 & .87 \\
Bloque 6 & 8.27 & 3.70 & .54 & .87 \\
Bloque 7 & 5.62 & 3.04 & .42 & .87 \\
Bloque 8 & 2.25 & 2.23 & .64 & .86 \\
Bloque 9 & 3.88 & 1.65 & .71 & .86 \\
Bloque 10 & 3.05 & 2.40 & .70 & .86 \\
Bloque 11 & 2.49 & 1.18 & .68 & .86 \\
Bloque 12 & 5.29 & .47 & .87 \\
Bloque 13 & 1.23 & .98 & .47 & .86 \\
Bloque 14 & 4.07 & .64 & .86 \\
Bloque 15 & 1.57 & .65 & .86 \\
Bloque 16 & 1.62 & .61 & .87 \\
Bloque 17 & 2.28 & 2.87 & .35 & .87 \\
Bloque 18 & 3.60 & 1.89 & .45 & .80 \\
Bloque 19 & 5.22 & 2.01 & .57 & \\
\hline
\end{tabular}

Alfa del mdulo $=.88$

$r_{\text {itc }} .20$

D.S. = 1.22), y el bloque 1, que evalúa plurales de singulares terminados en vocal $(\mathrm{M}=6.62$ y D.S. $=.95)$. Las correlaciones bloque-test están comprendidas entre .20 y .71 , observándose que todos los bloques obtienen correlaciones significativas, siendo los bloques más discriminativos el bloque 9 (formas verbales irregulares en pasado) y el bloque 10 (formas verbales irregulares en futuro).

El alfa de Cronbach, calculado para el módulo, alcanza un valor muy alto (.88), de manera que se puede decir que el módulo de morfología adaptado nos permite obtener puntajes confiables.

Asimismo, se puede apreciar que 8 de los 19 bloques alcanzan coeficientes de consistencia interna muy adecuados, que van de .91 a .79 y 4 bloques alcanzan coeficientes comprendidos entre .70 y .68 (aceptados).

\section{Validez}

Ha sido desarrollada para brindar un diagnóstico válido y confiable del desarrollo morfológico en sujetos 
cuyas edades están comprendidas entre los 6 y los 8 años. Con el propósito de validar el módulo como una medida del desarrollo morfológico, se ha estudiado la validez de criterio y de constructo, esta última evaluada mediante el análisis factorial.

Con relación a la validez de contenido (tema no estudiado en esta investigación), la estructura de ítems y bloques deja patente el tipo de respuesta deseada sin que pueda ser motivo de confusión la habilidad medida. Su contenido está bien definido, igual que la reacción esperada en sus ítems (Puyuelo, 1998).

\section{Validez de constructo}

\section{a) Correlación entre bloques}

Como observamos en la tabla 7 de la matriz de correlaciones, entre los 19 bloques y las puntuaciones totales de la prueba de morfología de la batería BLOC, se aprecia 19 correlaciones con coeficientes entre .34 y .79. Así, de 19 posibles correlaciones encontramos 17 correlaciones significativas: 5 de ellas entre .70 y .79 (muy significativas) y 12 correlaciones entre .40 y .66 (significativas). Los bloques que mejor correlacionan con el puntaje total de la prueba son el bloque 8 (formas verbales irregulares en presente), el bloque 9 (formas verbales irregulares en pasado), el bloque 10 (formas verbales irregulares en futuro), el bloque 11 (participios) y el bloque 15 (adjetivos derivados).
En el análisis de las correlaciones entre los bloques se observan que de las posibles 171 asociaciones, 138 tiene correlaciones significativas que van de .20 a .62. El bloque 9 (formas verbales irregulares en pasado) tiene correlaciones significativas con todos los otros bloques. Los bloques que mejor correlacionan entre sí son el bloque 11 (participios) con el 9 (formas verbales irregulares en pasado) y el 11 con el bloque 10 (formas verbales irregulares en futuro).

\section{b) Análisis factorial}

Con la finalidad de evaluar la viabilidad del análisis factorial para determinar la validez de constructo del módulo de morfología de BLOC, se emplearon dos pruebas, cuyos resultados se aprecian en la tabla 8: la medida de adecuación del muestreo Kaiser-Meyer y Olkin (K-M-O) y el test de esfericidad de Barlett. Para la primera, que es una medida de adecuación a la muestra, el puntaje fue de .82 , que es considerado bueno, y para el segundo se halló un puntaje de 592.361, que también resultó ser significativo al 1\%. Estos resultados permitieron continuar con el análisis factorial exploratorio.

Para el estudio de la estructura factorial subyacente del módulo de morfología de BLOC para la muestra total, se ha usado el método de extracción de los componentes principales y la rotación ortogonal a través del método Equamax. 


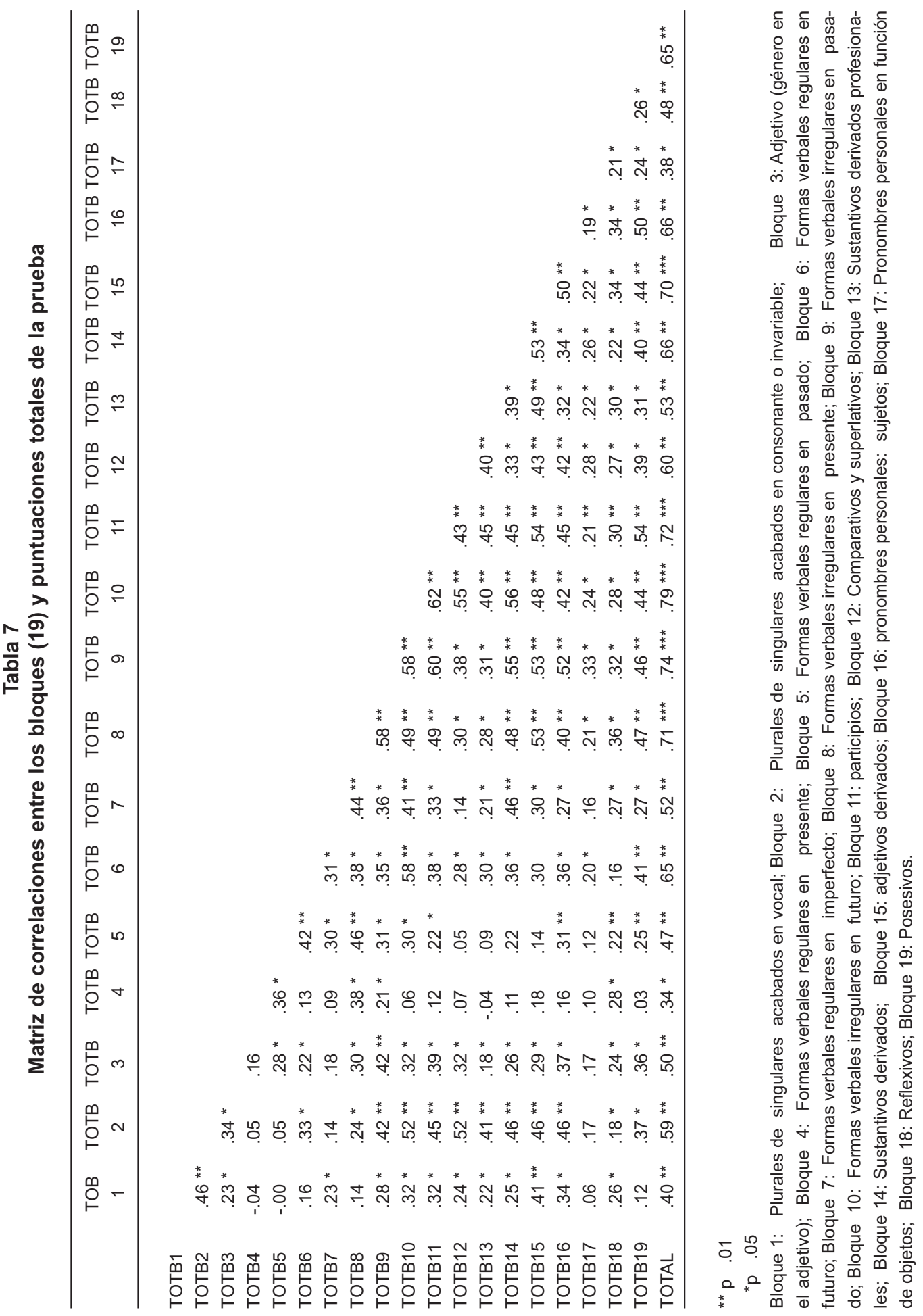


Como puede observarse en la tabla 8 , el análisis factorial exploratorio indicó la existencia de cinco factores, los cuales permiten explicar el $60,89 \%$ de la varianza total.

La agrupación de los bloques en estos cinco factores no permite una explicación coherente de los hallazgos. Esto podría deberse al tamaño de la muestra estudiada (lo que genera una relación entre número menor de sujeto por factor) y a la edad de los participantes, por ello sería conveniente replicar este análisis.

Tabla 8

Análisis factorial exploratorio del módulo de sintaxis de la Batería de Lenguaje Objetiva y Criterial $(N=90)$

\begin{tabular}{|c|c|c|c|c|c|}
\hline Bloques & 1 & 2 & 3 & 4 & 5 \\
\hline TOTB5 & .725 & & & & \\
\hline TOTB6 & .693 & & & & \\
\hline TOTB10 & .556 & & & & \\
\hline TOTB19 & .536 & & & & \\
\hline TOTB16 & .503 & & & & \\
\hline TOTB9 & .484 & & & & \\
\hline TOTB11 & .423 & & & & \\
\hline TOTB1 & & .777 & & & \\
\hline TOTB2 & & .722 & & & \\
\hline TOTВ17 & & & .840 & & \\
\hline TOTB12 & & & .615 & & \\
\hline TOTB4 & & & & .701 & \\
\hline TOTB18 & & & & .695 & \\
\hline ТОTВ3 & & & & .457 & \\
\hline TOTB8 & & & & .456 & \\
\hline TOTB7 & & & & & .593 \\
\hline TOTВ14 & & & & & .548 \\
\hline TOTB13 & & & & & .530 \\
\hline TOTB15 & & & & & .441 \\
\hline Eigenvalue & 6.06 & 1.95 & 1.26 & 1.19 & 1.10 \\
\hline \% Varianza explicada & 13,90 & 12,78 & 12,38 & 11,18 & 10,65 \\
\hline
\end{tabular}

\% Varianza total explicada: 60,89

Determinante $=.0000008453$

Medida de adecuación muestral de Kaiser-Meyer-Olkin $=.82$

Prueba de esfericidad de Barlett - Chi Cuadrado $=592.36 \mathrm{gl}=171 \mathrm{p}=.001$

$$
\begin{aligned}
& { }^{* *} p<.01 \\
& { }^{*} p<.05
\end{aligned}
$$




\section{Validez relacionada con el criterio}

a. Análisis comparativos entre los grupos por diagnóstico de lenguaje

En la tabla 9 se presentan las medias, desviaciones estándares de los 19 bloques para los grupos según diagnóstico de trastorno de lenguaje. Se señalaron las diferencias significativas para las comparaciones de medias mediante la Prueba U de Mann-Whitney.
En las comparaciones de las puntuaciones totales de los bloques según diagnóstico del lenguaje, se encuentra que existen diferencias estadísticamente significativas entre la mayoría de bloques.

No existen diferencias significativas para los bloques 1 (plurales de singulares acabados en vocal), 4 (verbos regulares: presente), 5 (formas verbales regulares en pasado) y 17 (pronombres personales en función de objetos) y 18 (reflexivos) (véase tabla 10).

Tabla 9

Comparación de medias de los puntajes de los bloques y puntajes totales entre los grupos según diagnóstico del lenguaje

\begin{tabular}{|c|c|c|c|c|c|}
\hline \multirow[t]{2}{*}{ Bloques } & \multicolumn{2}{|c|}{$\begin{array}{l}\text { Sin trastorno del lenguaje } \\
\qquad N=90\end{array}$} & \multicolumn{2}{|c|}{$\begin{array}{l}\text { Con trastorno del lenguaje } \\
\qquad N=32\end{array}$} & \multirow[t]{2}{*}{$\begin{array}{l}\text { U Mann } \\
\text { Whitney }\end{array}$} \\
\hline & $M$ & MR & $M$ & MR & \\
\hline 1 & 64.27 & 5784.0 & 53.72 & 1719.0 & -1.76 \\
\hline 2 & 68.64 & 6178.0 & 41.41 & 1315.0 & -3.81 ** \\
\hline 3 & 65.96 & 5936.0 & 48.95 & 1566.5 & -3.22 ** \\
\hline 4 & 61.94 & 5574.5 & 60.27 & 1985.5 & -0.53 \\
\hline 5 & 64.56 & 5810.5 & 52.89 & 1692.5 & -1.65 \\
\hline 6 & 66.98 & 6028.5 & 46.08 & 1474.5 & -2.90 ** \\
\hline 7 & 67.91 & 6112.0 & 43.47 & 1391.0 & -3.50 ** \\
\hline 8 & 65.48 & 5893.5 & 50.30 & 1609.5 & $-2.10 *$ \\
\hline 9 & 69.51 & 6255.5 & 38.98 & 1247.5 & -4.27 ** \\
\hline 10 & 69.64 & 6268.0 & 38.59 & 1235.0 & -4.39 ** \\
\hline 11 & 68.81 & 6192.5 & 40.95 & 1310.5 & -3.88 ** \\
\hline 12 & 64.97 & 5847.0 & 51.75 & 1656.0 & $-2.10^{*}$ \\
\hline 13 & 67.03 & 6032.5 & 45.95 & 1470.5 & -2.93 ** \\
\hline 14 & 69.06 & 6215.5 & 40.23 & 1287.5 & $-4.07^{\star *}$ \\
\hline 15 & 67.34 & 6060.5 & 45.08 & 1442.5 & -3.12 ** \\
\hline 16 & 66.96 & 6026.5 & 46.14 & 1476.5 & $-2.88^{\star *}$ \\
\hline 17 & 62.78 & 5650.5 & 57.89 & 1852.5 & -0.79 \\
\hline 18 & 62.89 & 5660.0 & 57.59 & 1843.0 & -0.74 \\
\hline 19 & 66.72 & 6005.0 & 46.81 & 1498.0 & $-2.76^{* *}$ \\
\hline
\end{tabular}

* p. $<.05$

${ }^{* *}$ p. $<.01$ 
Tabla 10

Comparación de medias de los puntajes totales entre los dos grupos según diagnóstico del lenguaje

\begin{tabular}{|c|c|c|c|c|c|}
\hline \multirow{3}{*}{ Bloques } & \multirow{2}{*}{\multicolumn{2}{|c|}{$\begin{array}{l}\text { Sin trastorno del lenguaje } \\
\qquad N=90\end{array}$}} & \multicolumn{3}{|c|}{ Con trastorno del lenguaje } \\
\hline & & & & & $\mathrm{T}$ \\
\hline & $\mathrm{M}$ & D.S. & $\mathrm{M}$ & D.S. & \\
\hline Total & 89.39 & 21.92 & 67.09 & 21.31 & $4.98^{* *}$ \\
\hline
\end{tabular}

En la tabla 10 se presentan las medias, desviaciones estándares de los totales para los grupos según diagnóstico de trastorno de lenguaje. Se señalaron las diferencias significativas para las comparaciones de medias mediante la prueba $t$ de Student. En lo que concierne al análisis de las puntuaciones totales para los grupos según diagnóstico de trastorno de lenguaje, apreciamos que existen diferencias estadísticamente significativas entre los dos grupos $(\mathrm{t}=4.98)$. El grupo de los niños $\sin$ trastorno de lenguaje alcanza las puntuaciones más elevadas $(\mathrm{M}=89.39$, D.S. $=21.92)$ en comparación con los alumnos con diagnóstico de trastorno de lenguaje $(\mathrm{M}=67.09$, D.S. $=21.31)$.

\section{b. Análisis comparativo por edades}

En la tabla 11 se presentan las diferencias de las medias de los bloques y de los puntajes totales, así como los valores F. Se señalaron las diferencias significativas para las comparaciones de medias mediante la prueba Anova.
En las comparaciones de las puntuaciones totales por grupos de edad, se encuentra que existen diferencias estadísticamente significativas entre todos los grupos, con una diferencia mayor entre los grupos de 6 y 8 años.

Del análisis de las comparaciones de las puntuaciones de los bloques por grupo de 6 y 8 años, se puede apreciar que existen diferencias significativas entre la mayoría de los bloques, con excepción de: 1 (plurales de singulares acabados en vocal), 3 (adjetivos), 4 (formas verbales regulares en presente) y 14 (sustantivos derivados).

Existen diferencias estadísticamente significativas en la comparación de 6 de los 19 bloques para los grupos de 6 y 7 años. Estas diferencias se aprecian en los bloques: 7 (formas verbales regulares en imperfecto), 8 (formas verbales irregulares en presente), 9 (formas verbales irregulares en pasado) 13 (sustantivos derivados profesionales), 14 (sustantivos derivados) y 16 (pronombres personales).

Asimismo, existen diferencias significativas para 8 de los 19 bloques, 
entre los grupos de 7 y 8 años: bloque 6 (formas verbales regulares en futuro), bloque 9 (formas verbales irregulares en pasado), bloque 10 (formas verbales irregulares en futuro), bloque 12 (comparativos y superlativos), bloque 14 (sustantivos derivados), bloque 17 (pronombres personales en función de objetos, bloque 18 (reflexivos) y bloque 19 (posesivos.)
En las comparaciones de los bloques 1 (plurales de singulares acabados en vocal), 3 (adjetivos) y 4 (formas verbales regulares en presente) no se observan diferencias significativas entre ninguno de los grupos de edad.

Las comparaciones del bloque 1 (plurales de singulares acabados en vocal) entre los grupos de edad y los grupos según diagnóstico no presentan diferencias significativas.

Tabla 11

Comparación de medias de los Bloques para grupos comparado de edad y prueba post hoc de Scheffé

\begin{tabular}{|c|c|c|c|c|}
\hline \multirow[b]{2}{*}{ Bloques } & \multicolumn{3}{|c|}{ Grupos de edad comparados } & \multirow[b]{2}{*}{$\mathrm{F}$} \\
\hline & $\begin{array}{c}\text { 6-7años } \\
\text { Diferencias de } \\
\text { medias }(\mathrm{I}-\mathrm{J})\end{array}$ & $\begin{array}{c}\text { 6-8 años } \\
\text { Diferencias de } \\
\text { medias (I-J) }\end{array}$ & $\begin{array}{c}\text { 7-8 años } \\
\text { Diferencias de } \\
\text { medias (I-J) }\end{array}$ & \\
\hline 1 & -.14 & -.25 & -.11 & .70 \\
\hline 2 & -.91 & $-1.61 * *$ & -.70 & 8.93 \\
\hline 3 & -.14 & -.52 & -.38 & 1.92 \\
\hline 4 & -.71 & -1.40 & -.69 & 1.92 \\
\hline 5 & -.14 & $-1.22 *$ & -1.08 & 3.94 \\
\hline 6 & -.31 & $-3.05 *$ & $-2.74 *$ & 8.89 \\
\hline 7 & $-1.60 *$ & $-2.00 * *$ & -.40 & 5.36 \\
\hline 8 & $-1.51 *$ & $-2.29 * *$ & -.78 & 13.40 \\
\hline 9 & -.98 * & $-2.03 * *$ & $-1.04 * *$ & 19.49 \\
\hline 10 & -.76 & $-2.86 * *$ & $-2.11 * *$ & 19.24 \\
\hline 11 & -.95 & $-1.95^{* *}$ & -1.00 & 8.95 \\
\hline 12 & -.48 & -1.76 ** & $-1.28 * *$ & 9.31 \\
\hline 13 & -1.08 * & -1.58 ** & -.50 & 7.18 \\
\hline 14 & -.83 * & $-1.82^{* *}$ & -.99 ** & 16.83 \\
\hline 15 & -.78 & -1.50 * & -.72 & 9.83 \\
\hline 16 & -1.50 * & -2.70 * & -1.21 & 10.29 \\
\hline 17 & -.03 & -1.49 * & -1.46 ** & 8.66 \\
\hline 18 & -.72 & $-1.95 *$ & $-1.23^{* *}$ & 11.00 \\
\hline 19 & -.43 & -1.67 * & -1.24 ** & 6.71 \\
\hline TOTAL & $-13.99 *$ & $-33.65 *$ & -19.66 ** & 28.96 \\
\hline
\end{tabular}


Los alumnos de 6 años obtuvieron promedios aproximados a 7 o más en: el bloque 1, que mide plurales de sustantivos terminados en vocales $(\mathrm{M}=$ 6.50 y D.S. = 1.21); en el bloque 3, que evalúa el uso del género en el adjetivo $(\mathrm{M}=9.34$ y D.S. $=1.14)$ y en el bloque 5 , relacionado con las formas verbales en pasado $(\mathrm{M}=7.86$ y D.S. $=2.20)$. Estos datos indican que los alumnos dominan estas habilidades lingüísticas y pueden usarlas correctamente (interpretación referida al criterio, como mínimo el $70 \%$ de respuestas correctas en un bloque).

Los alumnos de 7 años obtuvieron promedios aproximados a 7 o más en: el bloque 1, que mide plurales de sustantivos terminados en vocales $(\mathrm{M}=$ 6.64 y D.S. $=.85$ ); en el bloque 3 , que evalúa el uso del género en el adjetivo $(\mathrm{M}=9.48$ y D.S. $=1.64)$ y en el bloque 5 , relacionado con las formas verbales en pasado $(\mathrm{M}=8.00$ y D.S. $=2.62)$. Estos datos indican que los alumnos dominan estas competencias lingüísticas y pueden usarlas correctamente (interpretación referida al criterio, $70 \%$ de respuestas correctas en un bloque).

Los alumnos de 8 años obtuvieron promedios aproximados de 7 o más en: el bloque 1, que mide plurales de sustantivos terminados en vocales $(\mathrm{M}=$ 6.75 y D.S. $=.65$ ); el bloque 2 , relacionado con plurales de sustantivos terminados en consonantes o invariables $(\mathrm{M}$ $=6.75$ y D.S. $=1.08$ ) el bloque 3 , que evalúa el uso del género en el adjetivo $(\mathrm{M}=9.86$ y D.S. $=0.49)$, el bloque 4, que estudia formas verbales regulares en presente $(\mathrm{M}=6.81$ y D.S. $=2.95)$, el bloque 5, relacionado con las formas verbales regulares en pasado $(\mathrm{M}=$ 9.08 y D.S. $=1.44$ ), el bloque 6 , relacionado con formas verbales regulares en futuro $(\mathrm{M}=7.67 \mathrm{y}$ D.S. $=2.65) \mathrm{y} \mathrm{el}$ bloque 16 , que mide pronombres personales, sujetos $(\mathrm{M}=6.61$ y D.S. $=$ .80) Estos datos indican que los alumnos dominan estas competencias lingüísticas y pueden usarlas correctamente (interpretación referida al criterio, $70 \%$ de respuestas correctas en un bloque como mínimo).

\section{Discusión de los resultados}

Los resultados encontrados en el análisis psicométrico demuestran que el módulo de morfología adaptado alcanza niveles de confiabilidad y validez aceptables, por lo que se puede sugerir su uso en una población semejante a la estudiada.

El análisis de la consistencia interna a través del coeficiente alfa para la muestra total de estandarización fue de .88 y los coeficientes, según diagnóstico, son .85 para el grupo sin trastorno de lenguaje y de .87 para el grupo con trastorno de lenguaje. Los coeficientes de consistencia interna que se obtuvieron para los grupos según edad fueron: .83 para el grupo de 6 años, .83 para el grupo de 7 años y de .80 para el grupo de 8 años. 
Estos hallazgos nos sugieren que:

Respecto de los 19 bloques analizados, notamos que 12 obtienen índices de confiabilidad aceptados comprendidos entre .91 y .68: los bloques 6,7 y 4 , referidos al conocimiento de la conjugación verbal con verbos regulares en tiempo futuro (.91), irregulares en tiempo imperfecto (.91) y regulares en tiempo presente (.86), respectivamente. A estos les siguen otros tres bloques, que tienen altos índices de confiabilidad: el bloque 17, referido a pronombres personales en función de objeto (.84), el 12 referido al conocimiento de los comparativos y superlativos (.81), y el 3, referido a la flexión del género en el adjetivo (.79). Continúan el bloque 10 referido al conocimiento de verbos irregulares en tiempo futuro (.79), el bloque 5 referido a verbos regulares en tiempo pasado (.77) y el bloque 11 que evalúa el participio. A continuación, el bloque 8 , concerniente a verbos irregulares en tiempo presente (.68). Todos estos bloques, excepto el bloque 8 , están conformados por todos sus ítems con altas correlaciones con el test. En el bloque 8, dos de sus diez ítems no son aceptados, con correlaciones ítem-test, de .07 y .03 para la conjugación en presente de la tercera persona del singular del verbo querer y la conjugación en presente de la primera persona de caber, respectivamente. En el primer caso, la conjugación del verbo querer, tanto en este bloque como en todos los otros en los que se solicita su conjugación, las correlaciones de este ítem con el test son bajas. Observándose las respuestas registradas se podría pensar que la lámina que acompañó la pregunta no evocó el verbo querer, los alumnos nombraron otros verbos, como por ejemplo comer, preparar, cenar, entre otros. En el segundo caso, el verbo caber es un verbo que podría ser de poco uso en nuestro medio, y se aprende a conjugar por enseñanza en la escuela después del tercer grado, y muchos de los alumnos seleccionados para esta investigación no cursaban el tercer grado.

En el bloque 19, relacionado con los posesivos (.69), solo uno de los ítems que lo componen no muestra buena relación con el test, el ítem 9, vinculado con el conocimiento y uso del pronombre suyo como posesivo, fue difícil para la mayoría del grupo de estandarización. Si este ítem se eliminase, el bloque podría contar con un coeficiente de confiabilidad de .70 .

En el bloque 2, referido a la formación de plurales de singulares terminados en consonantes e invariables, solo uno de los ítems no es aceptado, el 6 (plural de cactus, cuyo plural es invariante, es decir no se modifica al realizarse el plural). Este reactivo se presenta luego de cinco ítems, que varían al realizarse el plural. Si se eliminase este reactivo, el bloque podría alcanzar un coeficiente de confiabilidad de .70 para la población estudiada. 
A continuación encontramos el bloque 18 , concerniente al conocimiento de los reflexivos y recíprocos y otros pronombres que acompañan al verbo (.64). Dentro de este bloque se hallan cuatro de los ítems no aceptados: el 2 (se abrazan), el 5 (se llaman), el 9 (columpiarse) y el 10 (se duerme). Con relación a este último ítem, el 10, los autores de la prueba indican que su utilización puede ser opcional, no es significativa, pues la utilización del se al final del verbo dormir (se duerme), no tiene función reflexiva ni pronominal, solo indica un aspecto temporal de la acción verbal. El bloque 9 (columpiarse) mostró ser muy fácil para el grupo con el que se trabajó.

Le sigue el bloque 9, referido a verbos irregulares en tiempo pasado (.60). Tiene cuatro de los diez ítems no aceptados: el 2 (conjugación en pasado de la tercera persona del singular del verbo querer), el 8 (conjugación en tiempo pasado de la segunda persona del singular del verbo andar, anduviste), el 9 (conjugación en tiempo pasado de la segunda persona del singular del verbo conducir, condujiste) y el 10 (conjugación en tiempo pasado de la primera persona del singular del verbo caber, cupe). Ningún niño de la muestra respondió a estos tres últimos ítems, pues son de poco uso en nuestro medio y se aprenden a conjugar en la escuela después del tercer grado.

Finalmente nos referiremos a los bloques 13, 1, 14 y 15. El bloque 13, referido a la formación de sustantivos derivados (.57), tiene dos de sus ítems no aceptados: el ítem 7 (artista, derivado de arte) y el 10 (química) que correlaciona negativamente con el test $(-.00)$.

El bloque 1, relacionado con la formación de plurales de singulares terminados en vocal, tiene 3 ítems que no correlacionan: el 1 (plural de gato, $g a-$ tos), el 2 (plural de mapa, mapas), y el 5 (plural de zorro, zorros). Estos tres ítems demostraron ser muy fáciles, tanto que en los casos de 1 y 2 todos los niños respondieron con éxito. Este bloque es el único bloque del módulo de morfología que tampoco tiene fiabilidad en la prueba original, según reportan los autores en el manual.

El bloque 14, referido a la formación de sustantivos derivados (.51), tiene cinco de sus diez ítems que no correlacionan con el test: el ítem 2 ( $a b u$ rrimiento), el 3 (agotados), el 6 (planetario), el 9 (soledad) y10 (sordera). En todos los casos se observó diversidad de respuestas; en ocasiones los alumnos no se percataron del sustantivo que se le solicitaba derivar y en otras se les dificultó la derivación, como en el caso de sordera, derivado del sustantivo sordo, del cual se obtuvieron respuestas, como sordidadidad, sordedad, sordería.

A partir de este análisis es importante señalar que los siete bloques que presenta la prueba para evaluar el conocimiento de la conjugación del 
verbo han mostrado buenos índices de confiabilidad comprendida entre $.91 \mathrm{y}$ .69. Los ítems que han sido rechazados en estos bloques están relacionados, en algunos casos, con conocimientos que se aprenden luego del tercer grado de primaria de nuestros colegios y, en un caso, por estar acompañados por una lámina que no evocó el verbo en el caso del verbo querer.

En relación con la validez de constructo mediante el análisis de interbloques, se puede observar que todos los bloques correlacionan significativamente con el puntaje total de la prueba. Igualmente existen correlaciones entre la mayoría de los bloques, así, de 171 posibles correlaciones, encontramos 138 correlaciones significativas. Existen tres correlaciones negativas no significativas.

Del análisis factorial, también relacionado con el cálculo de la validez de constructo se puede observar la existencia de cinco factores, los cuales permitieron explicar el $60,89 \%$ de la varianza total. Sin embargo, no se logró una explicación coherente de la agrupación de los bloques en los cinco factores. Un estudio en grupos de edades mayores quizá podría darnos una explicación afín.

El cálculo de la validez con relación al criterio se realizó mediante el análisis comparativo entre grupos de estudio. En una primera exploración se compararon las muestras de los grupos según diagnóstico del lenguaje (niños con trastorno y niños sin trastorno de lenguaje) y en un segundo análisis se realizó la comparación de las puntaciones por grupos de edades.

El primer análisis comparativo (niños con trastorno y niños sin trastorno de lenguaje) permite apreciar diferencias significativas entre los puntajes totales de los dos grupos comparados, así como entre la mayoría de los bloques, con excepción de: 1 (plurales de singulares acabados en vocal), 4 (verbos regulares: presente), 5 (formas verbales regulares en pasado) y 17 (pronombres personales en función de objetos) y 18 (reflexivos).

Del análisis comparativo de las puntuaciones totales para los grupos de edades, se puede apreciar que existen diferencias significativas entre los tres grupos, con una mayor diferencia entre los grupos de 6 y 8 años. Asimismo, del análisis comparativo de los 19 bloques entre los grupos de 6 y 8 años se puede apreciar que existen diferencias significativas para la mayoría de los bloques, con excepción de 1 (plurales de singulares acabados en vocal), 3 (adjetivos), 4 (formas verbales regulares en presente) y 14 (sustantivos derivados).

En la comparación de los grupos de 6 y 7 años, existen diferencias estadísticamente significativas entre 6 de los 19 bloques. Igualmente, existen diferencias significativas entre los grupos de 7 y 8 años para 9 de los 19 bloques.

No se encontraron diferencias importantes en la comparación de los gru- 
pos según diagnóstico y según grupos de edad en el bloque 1.

Los alumnos de 6 y 7 años respondieron $70 \%$ o más ( 7 o más de las 10 preguntas) de los bloques 1,3 y 5 , indicando dominar los conocimientos relacionados con el uso de plurales terminados en vocales, uso de morfemas de género en adjetivo y el pasado de verbos regulares.

Los alumnos de 8 años respondieron $70 \%$ o más de los bloques ( 7 o más preguntas) de los bloques $1,2,3,4,5$, 6 y 16 , relacionados con el uso de morfemas para plurales de sustantivos terminados en vocales, consonantes e invariables, uso de morfemas para el género en el adjetivo, uso de verbos regulares en presente, pasado y futuro y pronombres posesivos. Con relación a la conjugación de verbos, los niños de 8 años aún no mostraron dominio en el uso de verbos regulares en imperfecto ni en la conjugación de verbos irregulares requeridos por el módulo.

\section{Conclusiones}

1. Las modificaciones lingüísticas de 15 ítems del módulo de morfología de la batería BLOC original fueron aceptadas por los jueces participantes.

2. Los puntajes del módulo de morfología de la batería BLOC obtenidos en los grupos estudiados presentan confiabilidad por consistencia interna.

3. El módulo de morfología de la batería BLOC presenta validez de constructo a través del método intraprueba al analizar las correlaciones bloque-módulo en cada uno de los bloques.

4. El módulo de morfología de la batería BLOC presenta validez de constructo a través del método intraprueba, la matriz de correlaciones entre bloques presenta asociaciones estadísticamente significativas.

5. El módulo de morfología de la batería BLOC presenta validez relacionada con el criterio a través del método de la comparación de grupos por diagnóstico.

6. El módulo de morfología de la batería BLOC presenta validez relacionada con el criterio a través del método de la comparación de grupos por grupos de edad.

7. Los alumnos de 8 años mostraron dominio en las competencias lingüísticas relacionadas con los bloques 1 y 2 (uso de morfemas en la formación de plurales), en el bloque 3 (uso de morfemas en la formación del género en el adjetivo), en los bloques 4, 5, 6 (conjugación de verbos regulares en presente, pasado $\mathrm{y}$ futuro) y en el bloque 16 (pronombres posesivos).

\section{RECOMENDACIONES}

- Realizar la adaptación psicométrica y baremación del módulo de morfología de la batería BLOC en otros grupos de edades. 
- Realizar la adaptación psicométrica y baremación de los módulos de sintaxis, semántica y pragmática de la batería BLOC, de esta forma podríamos contar con una batería para medir el lenguaje y sus tres componentes: contenido, uso y forma en niños mayores de 4 años.

- Realizar la adaptación psicométrica de la batería BLOC-S (Batería de Lenguaje Objetiva CriterialScreening), elaborada con ítems seleccionados de la batería BLOC, la que nos podría permitir una detección rápida de dificultades de lenguaje $o$, específicamente, de algunos de sus componentes.

- Para estudiar la morfología de niños de 6, 7 y 8 años, utilizar solo los bloques 1 (plurales de sustantivos terminados en vocales), 2 (plurales de sustantivos terminados en consonantes o invariables), 3 (uso de género en el adjetivo), 4 (conjugación de verbos regulares en presente), 5 (conjugación de verbos regulares en pasado), 6 (conjugación de verbos regulares en futuro) y 16 (pronombres personales) del módulo de morfología de BLOC (competencias lingüísticas en donde los niños de 8 años demostraron $70 \%$ o más de dominio).

- Realizar la adaptación psicométrica de la batería de lenguaje, apta para niños menores de 6 años, por ejemplo, podría ser PLON (Prueba de Lenguaje Oral de Navarra), que también evalúa igual que BLOC, uso, contenido y forma del lenguaje. Con la adaptación de esta prueba podríamos contar con una batería completa para niños de 4 a 6 años.

- Llevar a cabo estudios de la evolución de las competencias lingüísticas representadas por los bloques del módulo (la prueba es flexible en la administración, permite aplicar el módulo o solo un bloque del módulo en un amplio intervalo de edad) a fin de conocer el desarrollo lingüístico infantil en nuestro medio.

- Se sugiere la aplicación de la prueba por parte de psicopedagogos, psicólogos y terapeutas del lenguaje a niños con necesidades especiales con fines de diagnóstico, intervención y seguimiento. 
Tabla 12

Percentiles de los Bloques del Módulo de Morfología para 6 años ( $N=30)$

\begin{tabular}{|c|c|c|c|c|c|c|c|c|c|c|c|c|c|c|c|c|c|c|c|}
\hline & B1 & B2 & & B4 & B5 & B6 & B7 & B8 & B9 & B10 & B11 & B12 & B13 & B14 & B15 & B16 & B17 & B18 & B19 \\
\hline 0 & & & & 10 & 3 & 20 & 50 & 7 & 13 & 53 & 3 & 83 & 13 & 33 & 10 & 10 & 77 & 13 & 7 \\
\hline 1 & & & & 17 & & 23 & 70 & 17 & & 60 & & 87 & 17 & 37 & 43 & 20 & 87 & 47 & 17 \\
\hline 2 & & 3 & & 23 & & 40 & 87 & 43 & 47 & & 13 & & 23 & 70 & 67 & 30 & 93 & 70 & 27 \\
\hline 3 & & & & 33 & 7 & 43 & 93 & 67 & 80 & 77 & 27 & & 50 & 90 & 83 & 40 & 97 & 83 & 50 \\
\hline 4 & & 17 & & 37 & & 47 & & 80 & 93 & 87 & 33 & 93 & 80 & 99 & 90 & 53 & & & 57 \\
\hline 5 & 13 & 53 & & 53 & 13 & 57 & & 93 & 99 & 93 & 57 & 97 & 93 & & 93 & 63 & 99 & 93 & 67 \\
\hline 6 & 37 & 70 & & 67 & 27 & 73 & & 99 & & 97 & 83 & & & & 99 & 83 & & 97 & 93 \\
\hline 7 & 93 & 90 & 7 & 70 & 30 & & 97 & & & & 93 & 99 & 97 & & & 90 & & 99 & 97 \\
\hline 8 & & 93 & 10 & 77 & 47 & 83 & & & & 99 & 97 & & 99 & & & 93 & & & 99 \\
\hline 9 & & & 20 & 90 & 77 & 90 & & & & & 99 & & & & & 97 & & & \\
\hline 10 & 99 & 99 & 99 & 99 & 99 & 99 & 99 & & & & & & & & & 99 & & & \\
\hline
\end{tabular}

Tabla 13

Percentiles del Puntaje Total del Módulo de Morfología para 7 años ( $N=30$ )

\begin{tabular}{|c|c|c|c|c|c|c|c|c|c|c|c|c|c|c|c|c|c|c|c|}
\hline PD & B1 & B2 & & B4 & B5 & B6 & B7 & B8 & B9 & B10 & B11 & B12 & B13 & B14 & B15 & B16 & B17 & B18 & B19 \\
\hline$\overline{0}$ & & & 3 & 3 & & 20 & 27 & & 3 & 13 & & 60 & & 10 & & 3 & 67 & 23 & 7 \\
\hline 1 & & & & 7 & & 23 & 37 & & 7 & 20 & & 63 & 3 & 23 & 7 & & 83 & 37 & 10 \\
\hline 2 & & 3 & & 17 & 7 & 27 & 50 & 17 & 30 & 37 & & 80 & 10 & 40 & 13 & 7 & 90 & 57 & 20 \\
\hline 3 & & 7 & & 33 & & & 60 & 30 & 53 & 60 & 3 & 87 & 20 & 70 & 30 & 10 & 97 & 77 & 30 \\
\hline 4 & & 13 & & 37 & & 30 & 67 & 43 & 70 & 87 & 13 & 93 & 43 & 90 & 67 & 23 & & 90 & 53 \\
\hline 5 & 10 & 23 & & 43 & & 37 & & 57 & 90 & 93 & 43 & & 60 & 99 & 93 & 37 & & 99 & 73 \\
\hline 6 & 27 & 53 & & 47 & 10 & 40 & 70 & 87 & 97 & 97 & 63 & 99 & 90 & & 97 & 53 & 99 & & 83 \\
\hline 7 & 93 & 83 & 7 & & 17 & & 80 & 97 & & 99 & 73 & & 97 & & 99 & 80 & & & 97 \\
\hline 8 & 99 & 93 & 10 & 60 & 37 & 53 & 87 & & & & 90 & & 99 & & & 90 & & & \\
\hline 9 & & 99 & 17 & 73 & 57 & 73 & 97 & 99 & & & 99 & & & & & 97 & & & 95 \\
\hline 10 & & & 99 & 99 & 99 & 99 & 99 & & & & & & & & & 99 & & & \\
\hline
\end{tabular}

Tabla 14

Percentiles del Puntaje Total del Módulo de Morfología para 8 años $(N=30)$

\begin{tabular}{|c|c|c|c|c|c|c|c|c|c|c|c|c|c|c|c|c|c|c|c|}
\hline PD & B1 & B2 & & B4 & B5 & B6 & B7 & B8 & B9 & B10 & B11 & B12 & B13 & B14 & B15 & B16 & B17 & B18 & B19 \\
\hline$\overline{0}$ & & & & 7 & & 3 & 23 & 7 & & 10 & & 33 & 3 & & & 3 & 50 & 7 & 3 \\
\hline 1 & & & & & & 7 & 43 & & & 13 & & 43 & 10 & 10 & 3 & & 53 & 23 & 7 \\
\hline 2 & & & & 13 & & & 63 & 10 & 10 & 23 & & 57 & & 27 & & 7 & 60 & 33 & 13 \\
\hline 3 & & & & 20 & & 10 & 67 & 20 & 33 & 33 & 10 & 63 & 27 & 50 & 23 & & 67 & 40 & 37 \\
\hline 4 & & & & & & 13 & 70 & 50 & 53 & 43 & 20 & 70 & 37 & 70 & 60 & 10 & 80 & 57 & 57 \\
\hline 5 & 7 & 7 & & 30 & & 17 & & 60 & 80 & 60 & 23 & 83 & 60 & 97 & 73 & 23 & 87 & 63 & 83 \\
\hline 6 & 10 & 37 & & 37 & 37 & 23 & & 70 & 99 & 83 & 50 & 93 & 70 & 99 & 83 & 47 & 90 & 80 & 87 \\
\hline 7 & 99 & 70 & & 50 & 50 & & 77 & 99 & & 90 & 73 & 99 & 87 & & 97 & 67 & & 99 & 97 \\
\hline 8 & & 93 & 7 & 67 & 67 & 43 & 83 & & & 99 & 87 & & 97 & & 99 & & 97 & & 99 \\
\hline 9 & & 99 & & 83 & 83 & 70 & 93 & & & & 99 & & 99 & & & 80 & & & \\
\hline 10 & & & 99 & 99 & 99 & 99 & 99 & & & & & & & & & 99 & 99 & & \\
\hline
\end{tabular}




\section{Ciccia}

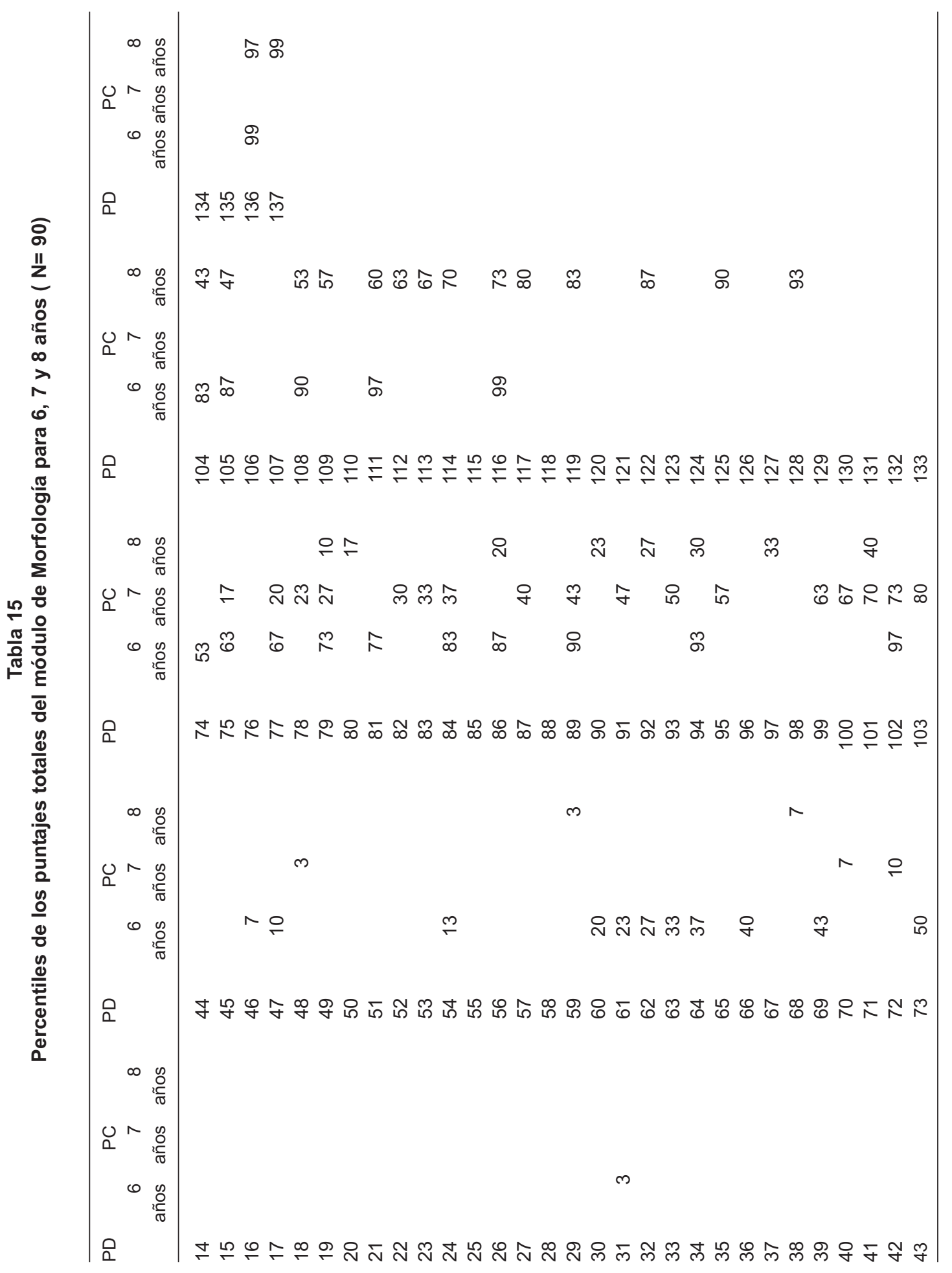




\section{REFERENCIAS}

Acosta, V. \& Moreno, A (1999). Dificultades del lenguaje en ambientes educativos. Del retraso al trastorno específico del lenguaje. Barcelona: Masson.

Aguado, G. (2000). El desarrollo del lenguaje de 0 a 3 años. Bases para un diseño curricular en la educación infantil. Madrid: CEPE.

Aguado, G. (1999). Trastorno específico del lenguaje. Retraso de lenguaje y disfasia. Málaga: Aljibe.

Aguado G. (1989). El desarrollo de la morfosintaxis en el niño. Madrid: CEPE.

Berko, J. \& Bernstein, H. (1999). Psicolingüística. 2.a edición. Madrid: McGrawHill.

Bloom, L. \& Lahey, M. (1978). Language development and language disorders. Nueva York: John Wiley and Sons.

Clemente, A. (1997). Desarrollo del lenguaje. Manual para profesionales de la intervención en ambientes educativos. 2.a reimpresión. Barcelona: Ediciones Octaedro.

De Vega, M. \& Cuetos, F. (Comps.) (1999). Psicolingüística del español. Madrid: Editorial Trotta.

Escurra, L.M (1988). Cuantificación de la validez de contenido por criterio de jueces. Revista de Psicología, 6(1-2), 103111.

Gili Gaya, S. (1979). Resumen práctico de gramática española. Barcelona: Biblograf.

Martínez, E. (1998). Lingüistica. Teorías y aplicaciones. Barcelona: Barcelona. S.A.

Matos, L. (1998). Análisis de la validez de la prueba Illinois de habilidades psico- lingüisticas (ITPA). Tesis para optar el título de licenciada en psicología. Universidad de Lima.

Muñiz, J. (1996). Psicometría. Madrid: Editorial Universitaria.

Nunnally, J. (1991). Teoría psicométrica. México: Editorial Trillas.

Ochoa, L. \& Giménez, J. A. Spanish 301 [en línea]. Gramática avanzada y composición. Fichas gramaticales. $<\mathrm{http}: / /$ artsandscience.corcordia.ca/cml 1/spanish/ochoa/301_Fichas-gramaticales.htm> [consulta: febrero del 2001]

Puyuelo, M.; Wiig, E.; Renom, J. \& Solanos, A. (1998). Batería de Lenguaje Objetiva y Criterial. Barcelona: Editorial Masson.

Puyuelo, M., Rondal, J. \& Wiig, E. (2000). Evaluación del lenguaje. Madrid: Editorial Masson.

Puyuelo, M.; Solanas, A.; Renom, J.; Wiig, E. (2002). BLOC. Screening. Barcelona: Editorial Masson.

Real Academia Española (1979). Esbozo de una nueva gramática de la lengua española. Madrid: Espasa Calpe.

Rodríguez, O.; Berruecos \& Paz, Ma. (1993). La adquisición del español como lengua materna. Bibliografía descriptiva. México D.F.: Colegio de México.

Sánchez, H. \& Reyes, C. (2002). Metodología y diseños en la investigación cientifica. Lima: Editorial Universitaria.

Rondal, J. \& Seron, X. (1995). Trastornos del lenguaje I. Lenguaje oral, escrito, neurolingüístico. Barcelona: Paidós. 